\title{
Interaction Symbolic on the Therapeutic Communication between Midwife and Patient
}

\author{
Indirawaty \\ Politeknik Kesehatan Kemenkes \\ Makassar \\ Makassar, Indonesia
}

\author{
Syamsuddin \\ Universitas Islam Negeri Alauddin \\ Makassar, Indonesia
}

\author{
S. Rustadi \\ Sekolah Tinggi Ilmu Kesehatan \\ Tanah Wali \\ Takalar, Indonesia
}

\begin{abstract}
The implementation of social interaction pattern between midwife and patients is important to explore due to the interaction is expected to be more effective helping for delivering baby process. This study aims to describe the implementation of social interaction by the midwife to the patient during the delivering baby, which is attributed to the model of therapeutic communication as a medium for efficient interaction through symbolic interactions. The method used in this research is qualitative obtained using digital internet research. Achievement of interaction pattern between midwife and patient is based on the therapeutic communication. The meaning is derived from pre interactions, which showed that the strategic steps undertaken by a midwife before beginning the interaction, the midwife prepared knowledge by analyzing the patient's book profile. Midwife visited the patients by greetings while asking the patient's condition politely in the introduction phase. Midwife constantly evaluated the patients' condition after social treatment in work phase. Midwife concluded that results of the patient progress during the treatment. The midwife made herself as therapeutics through various techniques of social interaction by optimal communication and changing the patient's behavior in a positive direction through the strengthening of the values of local wisdom that has become a tradition.
\end{abstract}

Keywords-interaction symbolic; therapeutic interaction; communication; midwife involvement.

\section{INTRODUCTION}

Midwife services system in Indonesia is based on care issues because of the empathy and a sense of care to the patient in compliance with excellent service. Determining the quality of services at the Hospital is based on the responsiveness of the patient. The health service at the hospital is a complex problem. Therefore, health service quality done by midwife should be considered professional. Satisfaction can be felt after the patient receiving the service. One of the factors that determine satisfaction is the quality of services, which is most indicated by the responsiveness of midwives.

Social phenomena at the hospital might be lack of social interaction with the patient due to midwife performed before the introduction so that patients sometimes feel uncomfortable. The midwife has knowledge of the childbirth and the type of therapy that will be used to the patient. Patients can only feel the pain since they strive to create tools through therapeutic communication in the form of verbal and even non-verbal. Therapeutic communication comprises the main key that will determine the success of a midwife during childbirth.

Social problems at the hospital environment associated with the interactions between midwife and the patient showed the gap between the ideal and factual midwife service quality. This is due to the demands of the patient and the lack the ability, knowledge, and skills of a midwife in serving patient. Interaction through clear and precise communication is important to provide effective service, and this is unique challenges in service. Hence, the midwife is required to perform interaction through therapeutic communication while behaving to the patient; the midwife should introduce themselves, explain what to do, make time contract to perform further midwifery behavior.

Social phenomenon between midwife and patients using analysis of symbolic interaction approach emphasizes that all be factual. Every part of interaction among individuals involves an exchange of symbols. When we interact with others, we are constantly looking for clues about whether the ideal type of behavior in that context and how to interpret what others expect. Symbolic interactions led to interactions among individuals and used to understand what other people say and do as an individual [1]-[3]. This paper explores the phenomenon of midwife interactions with patients when performing therapeutic communication approach such as those used when the nurses are serving patients. In the real interaction between midwife and patient, the midwife might show the low motivated behavior to the patient.

By the paradigm of midwifery, care given by midwives need critical thinking, responsible and rational decisionmaking to avoid unnecessary interventions that midwifery practice should be evidence base. One of the evidence base cares is mother's care during childbirth including providing emotional support, helping setting position, giving fluids and nutrients. Midwifery care is the implementation of the function and activity that is the responsibility of providing services to clients who have need and problem in the field of maternal health during pregnancy, maternity period, postpartum, infants after birth and family planning.

\section{RESEARCH METHOD}

This study applied qualitative method using digital internet research [4]. Relevant research concerning interaction symbolic on the therapeutic communication between midwife 
and patient was identified by searching the Google scholar for primary research material. The research databases were searched for publications from anytime to the present. These were interaction symbolic, therapeutic communication, and midwife and patient. No language restrictions were employed. The final step was in-depth references check. References that were insufficiently described were excluded.

\section{RESULTS AND DISCUSSION}

Midwives who perform therapeutic communication with patients should be able to recognize his/her well. He must be aware of who he is. This self-awareness is expected to be an objective to accept the differences and uniqueness of the patient. Communication preserve simply is effectual when the message is transmitted and received [5]. By communication process, information and understanding forwarded using symbols involving communicator, message, media, receiver, and feedback. The relationship between midwife and patient using therapeutic communication is conducted with the aim of improving the patient's emotions. Therapeutic communication is a mutual interaction between midwife and the patient during the childbirth aims at resolving the problems faced by patients. Therapeutic communication is communication that encourages the healing process of patients.

The midwife should understand and have the ability to listen actively and attentively. The fundamental issue of this communication is mutual need between the midwife and the patient to categorize into personal communication between the patient and midwife. The therapeutic relationship means an interaction that has therapeutic properties and different social relations. Therapeutic intimacy is a relationship of mutual help. This relationship is built for the benefit of patients, while social relationships are designed to meet the needs of both parties [6]. Stages of therapeutic communication is a cycle or steps that must be done in treatment. Therapeutic communication is not the same as social communication. The conducive environment can help patients to think clearly and express grievances suffered openly, complete systematic, and objective.

Paradigm Midwifery is a perspective of a midwife in providing services. The success of these services is affected by the knowledge and perspectives of a midwife about the reciprocal relationship between human, environment, behavior, health care/midwifery, and descent. Principles in midwifery care include providing the client the safety, satisfaction, self-determination, respecting cultural and ethnic diversity based on the context of the family-oriented promotions. A midwife is expected to provide care, prepared for the needs of mothers, babies and their families, supported by attention to individual autonomy, plotting the relationship with the mother and family, women's (family) is fully entitled to determine and decide on a plan of care. Considering the educational needs includes physical, psychological, social, cultural, spiritual and educational, underlying the invention is proven. Informing with full of empathy, consequence, trust, care to have a systematic approach to the assessment, planning, implementation, and evaluation, aware that pregnancy and childbirth is a physiological process. The effective communication system among midwife, women, and family as well as other health professionals recognize the importance of continuity of care in midwifery.

The theory of symbolic interactions is based on the pragmatism. Some of the viewpoints of symbolic interactions theory of George Herbert Mead are measuring groove pattern and focusing on stimulus and response [7]. The application of therapeutic communication between midwife and patient who performed pre-stage interaction before midwife takes care of patient's childbirth comprise a symbol to begin working. Despite the fact that the introduction or orientation phase, the action taken by a midwife is greeting the patient and sitting or standing before childbirth is a symbol that the midwife is ready to receive and communicate to the patient. A midwife is silent when communicating using therapeutic approach symbolizes that midwife is trying to listen and understand what the patient says.

The symbolic is a product of social interaction or modification of the social interaction [8]. Midwife when communicating to patients sometimes what is presented is insignificant but the midwife still trying to make sense of what the patient says because it helps childbirth. Therefore, midwife remains calm and relaxed respond to what the patient says. Honest attitude is very significant when communicating to the patient to understand what she/he wishes. Honesty is the main aspect to be able to communicate for valuable therapeutic.

Therefore, a midwife in communicating should use words that are easily understandable by the patient. Symbol works significantly in the social activities of individual than a nonsignificant gesture [9]. Thus, the greeting is a symbol that the midwife will begin her duties on the patient. Smiling or touching by the midwife to the patient is a symbol of attention and affection to the needs of the patient. When the patient gives information about the physical condition and the midwife listen carefully and act quickly to such information, such as patients experience pain after childbirth, the midwife acts quickly even when the patient experienced feeling better, and the midwife conveys important information and response quickly. Someone will put a sense of trust to the other person who is open and has a response that is not artificial. Otherwise, the patient would be cautious on the other person that is too smooth so often hides her heart's feeling or dishonest attitude.

Therefore, midwife mind in conveying information during the interaction to patients of prudent and fixed to the structure of the hospital rules. The concept of 'self' comprises a process that comes from the individual's social interaction with others; human behavior is not determined unanimously by the environment. In this case, the midwife accepts patient sincerely. Midwife continues to provide the patient assessment anticipating any actions that lead to slow healing or damaging the values that have been embedded. This is an expression of "self" to the midwife; however, the midwife does not accept the message from the patients as it is, but still doing surveillance. The attitude of midwife seems to be able to interpret the perspective of the community as a whole, interpret values and norms in a wide range of interactions in the environment or society. Groove society pattern based on 
Mead highlighted that the community showed an organized process and patterned interactions between individuals and among diverse groups. Society depends on the capacity of the individual, especially for the self-evaluation process in equaling with each other.

One of the attitudes between midwife and patients in dealing with the problems is always professional in taking action such as the families of patients who experienced childbirth. The patient's family or the patient herself is a member of the community is always changing constantly. The existence depends on the capacity of "self" or individual development is very dynamic. Society may change through the process shown by the concepts of mind and self through social interaction that is built, or another solution would be given to the patient's family. Social interaction between midwife and families of patients regarding medical expenses, finding a solution to the problems facing the families of patients can be resolved.

\section{CONCLUSION}

Therapeutic communication patterns determine the social interaction between midwife and patient as the implementation of social reality. Pre-interaction patterns indicate that early stages of a midwife when performing actions on the patient before the midwife interacts with patients because this stage determines the success of midwife in the act of childbirth. The midwife had to prepare either performance or patient medical record. The real introductory stage orientation or midwife implement the interaction in a tangible form with the patient in a way that midwife greet the patient for the first time before asking the patient's condition. Midwife showed the kind and polite attitude. Furthermore, the next stage is the real work which indicated that the social facts lead midwife to evaluate and treat the patient's condition by the duty midwife so that patients feel comfortable. The final stage is termination pattern that midwife performs social reality in the form of a reevaluation the development of the patient and conclude the development of the patient's condition to be reported to a doctor who deals with these patients.

\section{REFERENCES}

[1] H. S. Becker and M. M. McCall, Symbolic interaction and cultural studies. University of Chicago Press, 2009.

[2] H. Blunter, "Society as symbolic interaction," Symb. Interact. An Introd. to Soc. Psychol., vol. 263, 1994.

[3] R. C. Prus, Symbolic interaction and ethnographic research: Intersubjectivity and the study of human lived experience. SUNY press, 1996.

[4] D. Silverman, Qualitative Research. SAGE Publications, 2016.

[5] M. B. Johnson, "Communication in the Classroom.," 1999.

[6] B. Kozier, Fundamentals of nursing: concepts, process and practice. Pearson Education, 2008.

[7] G. H. Mead, Mind, self and society, vol. 111. Chicago University of Chicago Press., 1934.

[8] L. Quéré and G.-H. Mead, "La chose physique," Réseaux, vol. 15, no. 85, pp. 195-211, 1997.

[9] B. Gates, R. B. Ellis, and N. Kenworthy, Interpersonal Communication Nursing: Theory and Practice. Churchill Livingstone, 1995. 